\title{
The nature of epistemological opportunities for doing, thinking and talking about science : Reflections on an effective intervention that promotes creativity.
}

McGregor, D. , Frodsham, S. and Wilson, H.

Paper prepared for the Research in Science and Technology Education (RSTE) journal.

\begin{abstract}
Background: Randomised Control Trials (RCT) involving large numbers of schools, teachers and pupils, can provide statistically significant evidence that an intervention 'works', or makes a difference to learning. However, often the quantitative data collected to illustrate the extent of impact is insufficient to illustrate exactly 'how' the intervention was enacted, what was done and 'why' it was successful. This paper collates a range of forms of data from an innovative professional training programme to indicate the nature of the promoted strategies that comprise the 'intervention' and consider how they worked in practice.

Purpose: To illustrate how a mixed methods approach is required to substantiate the nature, as well as the extent of impact, of an educational intervention. Namely, Thinking Doing and Talking Science (TDTS).

Sample: The project reported on here involved 42 schools in a south east county in England, UK. 21 were the 'experimental' schools and 21 were 'control' schools.

Design and Methods: The project was an Educational Endowment (EEF) Funded RCT, designed to assess the impact of the TDTS intervention.

Results: Quantitative data showed TDTS had a statistically significant impact on the academic attainment of nine and ten-year olds, by an average of 3 months. The addition of the different forms of qualitative data provided here offer evidential insights illustrating how and why the intervention had the impact it did on thinking and attainment.

Conclusions: Designing research projects that examine both the nature and extent of impact on pupils' learning requires a mixed methods approach. This necessarily involves the statistical comparison of quantitative evidence from both the experimental and control school groupings. However, in addition to the quantitative data, qualitative evidence is required to elicit the precise nature of the intervention. This included observations during the professional development sessions, lesson transcripts, evaluative questionnaire data and interviews (with teacher and pupils) after in-service training each contributing to capturing a more comprehensive 'picture' of the key characteristics of a successful science learning intervention.
\end{abstract}

\section{Keywords}

thinking; doing; talking; science learning; quantitative and qualitative data

\section{Introduction}

In recent years, there has been an increase in educational research in England, seeking substantial quantitative evidence of teaching innovations to statistically prove something 'works' (British Educational Research Association, BERA, 2018; EEF, 2019a). The Education Endowment Foundation (EEF) has been at the forefront of this work, being an independent charity 'dedicated to breaking the link between family income and educational achievement' and to generating evidence of 'what works' to improve learning (EEF, 2019a). A Randomised Controlled Trial (RCT), that compares the attainment performance of two cohorts of an 'experimental' and 'control' group is their favoured approach. 
Recent EEF evaluations (EEF 2018, 2019b, 2019c) have shown that the impact of three different teaching interventions, applied in classrooms of pupils aged nine and ten years old across more than 120 schools in the United Kingdom (with 100s of children involved), provided between 2 and 3 months additional progress in one year. The three interventions were Thinking Doing Talking Science, TDTS, (EEF 2018), Philosophy for Children (P4C), (EEF 2019b) and Dialogic Teaching, DT, (EEF 2019c). Each of these focused on promoting cognitive development, albeit in different ways, to improve learning. The EEF summarises them as follows: TDTS 'makes science more practical, creative and challenging'; P4C promotes pupils 'asking questions, constructing arguments and engaging in reasoned debates' and DT is 'cognitively challenging' and promotes 'talking'.

The three interventions have been statistically shown to make a difference to nine and tenyear olds' attainment, but the pedagogical nuances (Bennett et al 2018) required to sustain the marked impact for each require further clarification. This is because there are numerous teaching approaches that challenge learners and encourage them to 'think', 'talk' and 'do', for example. There is also some tension surrounding the nature of RCTs and the claims that can be made about these successful interventions. For example, whilst Connelly et al (2017) concluded that their systematic review of over one thousand $(n=1017)$ RCTs, carried out in educational settings, was a valid approach to assess the impact of a pedagogic innovation the study highlighted how a significant number of projects reviewed, nearly $40 \%$, 'failed to reflect upon the implications of their findings for theory' (ibid:289). Wyse et al (2018) also indicated that 'less strong research' [submitted for the Research Excellence Framework, REF, required periodically from all Higher Education Institutions in the UK to demonstrate the excellence of their research] was 'frequently insufficiently theorised to make a contribution to knowledge' (ibid:15). To this end this paper focuses on examining the theoretical intentions informing one of the three successful interventions evidenced by the EEF above, namely the TDTS approach.

By examining statistically the difference in the assessment performance data of the nine and ten year olds from the experimental and control groups, there was sufficient evidence to unequivocally claim that teachers, who were trained to deliver TDTS, improved their pupil's scientific attainment in academic tests by 3 months (EEF 2016). However, as Connelly et al's (2017) systematic review of RCTs in education indicated, exactly how the teacher's pedagogy changed and what kind of learning experience the pupils engaged in remained to be elicited and clarified further. Bennett et al (2018) highlighted how taking a mixed methods approach to evaluation (i.e. through the combination and triangulation of quantitative RCT data and qualitative information) findings can yield evidence of a more comprehensive and nuanced nature of an intervention. This paper, therefore, considers the statistical RCT findings alongside post-intervention evaluations from the experimental cohort (i.e. through teacher questionnaires, group interviews with pupils) as well as lesson transcripts and field observations of teachers rehearsing and reflecting on implementing the TDTS approach in the classroom. The findings and reflective discussion later in this paper illustrate how the interventional activities promote particular kinds of 'doing', 'thinking' and 'talking' related to science that support cognitive development and attainment.

\section{The TDTS intervention}

TDTS is an interactive 5-day professional development programme for teachers. It focuses on the development of creative and challenging science activities that encourage pupils to develop their thinking (Lewis and Smith, 1993; McGregor, 2007). Participating teachers were encouraged to enable their pupils to think and talk about scientific concepts through 
dedicated discussion times, to investigate ideas and problem solve and minimise pupils' writing and recording to allow more time for practical experiences. The intended aim was to enable participating teachers to make their science lessons more 'practical, creative and challenging' for pupils (EEF, 2016). Using 20-item tests as measures of pre and post attainment, the findings indicated how all pupils academically made approximately at least three additional months of progress as a result of engaging in the TDTS intervention. It is interesting to note that the EEF also highlighted the positive impact of four additional months of progress for girls. Additionally, all pupils eligible for Free School Meals (FSM) reportedly improved their academic performance by five months (EEF, 2016; Science Oxford, 2019). However, even these attainment measures pertaining to these specific groups do not elicit how or why the students improved their academic performance. The kind of constructive learning (and thinking) experiences that the teachers generated for their pupils (back in their own schools) is not evidenced through the statistical analysis of summative test scores (comprised of pupils' responses to 20 test questions before and after a year of being taught science differently). It is with the above in mind that this paper has been written, to elicit the nature of the TDTS approach that improved the academic performance of the nine and tenyear olds. Teacher in-situ practices were elicited and clarified in both an evidential and theoretical way. In the following sections of this article the ways that underpinning constructivist theory informs the TDTS approach has been demonstrated to illustrate how teachers have embraced constructivism and transformed their practice.

Theorising about constructivism that relates thinking and talking, emerging from doing Views of constructivism vary in the extent to which they draw on Piagetian notions of how children learn. Piaget $(1950 ; 1959)$ describes how when children encounter 'something' hitherto unknown to them, they wrestle with this 'new' information, observation or experience and cognitively re-structure what they retain (or assimilate) as their personalised interpretations of the world around them accommodate the new happenings (as suggested in Figure 1). The subsequent development of children's thinking, after successive experiences with the world around them, becomes more sophisticated (Piaget 1950 : 129). Over time they gradually re-structure their ideas to explain each new phenomenon as they encounter and interact with it. Piaget (1950) described how children's cognitive abilities followed a pattern of development through several hierarchical stages, from innate responses of a sensori-motor nature, to those that are conscious and reasoned at a later age. It is Piagetian constructivism that resonates with the TDTS intended aims. That is, to develop pupils' independent thinking (Science Oxford 2019) capability. The kinds of thinking promoted through TDTS are described in Table 1 (which summarises various cognitive processes that TDTS activities require pupils to engage in). When theorising ways to encourage pupils' thinking, Dewey (1910:215) indicated that what can often be assumed, or overlooked, needs to be brought into being and made explicit.

A person in pursuing a consecutive train of thoughts takes some system of ideas for granted (which accordingly he leaves unexpressed, unconscious) .....we have to turn upon some unconscious assumption and make it explicit.

Dewey (1910: 215)

This is what the TDTS programme promotes through the different strategies and this is achieved through thought processes coming into existence through talking and discussion. McGregor (2007, p. 255) summarises what Adey and Shayer (1994) suggest about 
developing academic success, through a focus on cognitive development. She synthesizes that is it is related to, 'creating challenging tasks', 'elucidating outcomes of thinking' and 'developing pedagogical frameworks with psychology of learning in mind'.

Each of the different strategies adopted by TDTS support and enable the practicing of various cognitive processes, so that the learners engage in a range of thinking experiences, which they can draw on in subsequent tasks, tests and assessments. The thinking promoted by the pedagogic strategies listed in Table 1 are designed to provide learning encounters that engage pupils in considering why something is, how it has come to be, how things are different and similar and what can be done to solve practical problems. How pupils engage and think about scientific ideas can also echo aspects of that demonstrated by scientists (McGregor and Frodsham, 2019). Plausible and reasoned thinking that draws on evidence is actively encouraged in TDTS lessons (as indicated in Figure 2). Piaget envisaged young learners as continuously striving to develop intellectually through self-construction and re-construction. That is, they think about what they observe is happening as they independently interact with the world and construe what this means in terms of their existing already assimilated, personal ontological truths (McGregor, 2007). Encountering new ways of thinking about science through the various activities (described in more detail later in this paper), such as Positive, Minus and Interesting (PMI) or considering how objects are similar or different through the Odd One Out (OOO) provide opportunities for the nine and ten year olds to think about the world around them and make sense of it. The Practical Prompts for Thinking (PP4T) resonate with Piaget's view of dissonance (1950) providing a stimuli for learners to think about things that don't make sense, offer a cognitive conundrum or perturbance from their perspective (like the round cake tin that rolls uphill) and making sense of it through the process of accommodation. It is the learners' cognitive re-structuring as a result of interacting with the world around them (and others') that is of significance in the TDTS approach and is summarised in Figure 1. Generalising about pedagogy that affords this kind of constructivist way of thinking and learning is summarised in Figure 2.

\section{Insert Table 1}

\section{Developing and supporting social constructivism to promote shared thinking in TDTS activities}

In contrast to Piagetian (1950) perspectives of self-construction, Vygotsky (1978) conceived the development of thinking and learning as social in its origin. For Vygotsky, language plays a formative role in the development of advanced mental processes. He also describes how:

'Children solve practical tasks with the help of their speech, as well as with their eyes and hands. This unity of perception, speech and action, which ultimately produces internalisation of the visual field, constitutes the central subject matter for any analysis of the origin of uniquely human forms of behaviour' (Vygotsky, 1978:26).

Through the practice of solving problems collectively pupils develop experience and confidence in manipulating objects and thinking about multiple ways to achieve resolutions or work towards goals they are aspiring to. Rehearsing approaches to solving a range of problems offers practise in knowing-how to tackle tasks with no specific correct outcome. McGregor (2007) describes how Vygotsky argued that social interactions with others (between peers, experts and novices) promotes discussion that heightens understanding about the matter in hand. Nine and ten-year olds, therefore, can work together toward joint 
solutions or resolutions that would be unattainable or beyond them if they were working alone as an individual. More social interaction and collaborative construing of ideas can therefore be supported by teachers (as characterised in Figure 3 ) to connect doing, talking, thinking through exchanges between the pupils, all within the community setting of the science classroom. The nature of interactions engaged in joint problem solving is assumed to develop the participants' zones of proximal development (zpd). Mediating and scaffolding (Griggs and McGregor 2012) are key to underpinning this Vygotskian perspective, which construes the zpd as the distance between the initial engagement and mastery of the task at hand. It is in this space that the TDTS activities provide varied ways to support learners in their problem-solving development.

\section{Insert Figure 1}

\section{Constructivist pedagogy that invites, shapes and encourages learners' thinking}

McGregor (2007:170) suggested that new '...innovative approaches' [like looking at everyday experiences, from an alternate more objective scientific perspective] often 'takes time' to develop. This may need nurturing [through interaction and discussion with a more able other] by extending the zpd (Vygotsky, 1978:86). Knowledge, accrued through activities, such as those described in Table 1, used to promote social constructivism extends learners' zpd. As learners acquire 'new' knowledge, through external stimuli, they 'check' it against pre-existing self-held knowledge. Reviewing and reflecting on what the new experience means is an active cognitive process brought about by disequilibrium, or some kind of disruption with existing beliefs or pre-conceptions. This 'new' experience or information, in a Piagetian perspective has to be re-thought about, accommodated and then assimilated as a 'reconstructed' concept. Providing fresh observations or experiences through the TDTS activities extends the opportunities for the learners to

'experience with hypothesizing and predicting, manipulating objects, posing questions, researching answers, imagining, investigating and inventing, in order for new constructions to be developed. From this perspective, the teacher cannot ensure that learners acquire knowledge just by having the teacher dispense it [...]. The learner must construct the knowledge' (Fosnot, 1989:20).

As Fosnot (2005) later elaborates, a constructivist view of learning suggests an approach to teaching that gives learners the opportunity for a concrete, contextually meaningful experiences through which they can search for patterns, raise questions; and model, interpret, and defend their strategies and ideas' (ibid: preface). Thus, teachers adopting PP4T, OOO, PMI and BQ activities and promoting a constructivist approach (as outlined above) present individual learners with varied opportunities to do, think and discuss and collaborators to engage in joint problems solving.

Constructivist teachers are, therefore, more concerned with processes of development and they encourage pupils to wonder why things are as they are (rather than those who are primarily concerned with their pupils learning scientific rules or laws). McGregor (2007:41) also describes how '[r]etention, understanding, and the active use of knowledge can be brought about only by the learning experiences in which learners think about and think with what they' have learned. To this end TDTS adopts a range of pedagogic approaches that engage learners beyond a narrow conceptualisation of learning science, from a focus on content or factual knowing-what to a focus on wondering about things, contemplating why they are so, thinking about possibilities and how to solve practical problems and designing 
solutions, practicing development of knowing-how. McGregor (2007: 166) considers this further when she highlights a range of factors affecting the cognitive processing that learners are guided to engage in, she also illustrates how practitioners could influence and support cognitive development through pedagogic tactics by presenting intriguing ideas, asking thought provoking questions, providing challenging tasks and reflecting on any outcomes. Mercer and Hodgkinson (2008) corroborate how it is also the teacher's pedagogical beliefs and practices (that is, the choices they make about how they communicate with their pupils and the strategies they use) that steers the nature of the thinking. Therefore, it is the teacher's understanding and interpretations of the philosophy of the teaching approach which informs the ways that pedagogical enactments emerge in the classroom. A teaching practice that deliberates on how and when to use particular materials, sequence and pose questions, encourage discussion, mediate without giving away any answers (McGregor 2007: 161 164) will affect how pupils engage in thinking. Pedagogic ways of facilitating practical experiences (by reducing the focus on writing, for example, in TDTS) becomes prominent and the concern with 'doing' and 'talking' (through small groups of pupils solving problems together) promote Vygotskian notions of social construction (McGregor 2007: 55) supporting learners in active and collaborative participatory learning. Teachers, therefore, as Mercer and Hodgkinson (2008), highlight will need to critically consider not only their questioning technique but also their mediation and scaffolding strategies to cultivate pupils' thinking rather than expositionally transmitting what is to be learned. It is with this theorisation in mind that Table 1 and Figures 1, 2 and 3 each summarise aspects of the TDTS approach to reflect how constructivist frameworks were (and are still being) adopted by the project.

Insert Figure 2 and 3

The strategies (OOO; PMI; BGs) outlined in table 1, adopted by the TDTS project to promote creative thinking have all been incorporated into the 'Bright Ideas Time' module, which can be found at http://www.pstt.org.uk/resources/continuing-professional-development/brightideas-in-primary-science.aspx.

\section{Research questions}

Having outlined the importance and influence of pedagogy on the nature of doing, thinking, and talking in classrooms, the following sections of the paper attempt to illustrate more specifically how the EEF (2016), funded TDTS project, 'support[ed] teachers to be more creative and thoughtful in planning their science lessons' and extending opportunities for pupils to do, think and talk about science. The transcription, observational and interview data discussed in the findings section suggest how constructivist theory has been translated and transformed into practice. With the TDTS strategies in mind, the following research questions will be considered. The responses to these questions will be presented through a range of data derived from reflections on training; evaluative questionnaires; focus group interviews with groups of six pupils (three boys and three girls) from seven participating schools, all situated in and around a south eastern county; researcher observations of the training sessions and finally the observed implementation of the approach in schools. The questions are:

1. What kinds of research methods can be applied to gather more qualitative evidence that complements the quantitative data demonstrating statistically that a particular intervention 'works'?

2. How does the intervention, TDTS, impact on teachers' practice to engage participating pupils in thinking and talking about science?

\section{Methodology}


To assess the way the TDTS intervention in primary science classrooms was enacted, a mixed methods approach was adopted. The quantitative evidence of a positive attainment impact has already been presented through EEF $(2016 ; 2018)$ reports. These publicly available documents illustrate at least a three-month improved performance by nine and tenyear old pupils (ibid) after they have engaged with the TDTS intervention. This paper considers how the implementation of additional research tools beyond just summative data in a mixed method research design (Sammons and Davis 2017) can offer insights as to why the TDTS approach was a success. The research design reported on here is a parallel mixed design (Teddlie and Sammons, 2010), whereby the quantitative data gathered through pre and post tests administered at the beginning and end of the project were complemented by the implementation of further research tools, gathering qualitative information throughout the project. The employment of various research instruments (such as the interviews, focus-group discussions and questionnaires) by researchers and not participants in the TDTS intervention sought to respond to both the research questions outlined earlier.

As non-participant observers, the researchers involved in this project endeavoured to objectively capture teacher and pupil reflections of the experiences of teaching and participating in the TDTS activities respectively. This was achieved by adopting a somewhat ethnographic narrative approach, similarly to Craft et al (2014). Craft et al employed surveys, observations and interviews to explore UK educators' (from primary to higher education) perspectives of creativity (ibid). Whilst Brewer (2000) may claim that ethnography should avoid surveys as a means to collect data, Cohen et al (2011) reported that this approach could examine multiple viewpoints and collate subjective understandings. Teachers were invited to complete questionnaires to elicit their understandings of the ways in which the TDTS had impacted on their teaching and learning in primary school science classrooms. Hetherington et al (2019) have more recently employed an electronic survey on an international scale, to primary and secondary school teachers, informal educators and teacher educators, to examine the relationship between science and creativity. Therefore, a written questionnaire exploring teachers' perspectives alongside other methods of data collection (i.e. focus group interviews; classroom and professional development observations) akin to Craft et al, would provide a more detailed description of the ways primary school practitioners, from the TDTS project, recounted they enacted their practice to support and develop their pupils' thinking in their science classrooms.

\section{Methods of data collection}

A two-cohort clustered RCT was carried out with the total sample of 42 schools in a county in south-east England that is relatively rural and has fewer English as an Additional Language (EAL) and Free School Meals (FSM) children compared to the national average. To qualify for FSMs, the annual family income is below a Government threshold that enables children from that household to receive cost-free meals at school. The teachers ( $>95 \%$ female) involved were usually two teachers of nine and ten-year old classes. If the school was small with only one class of nine and ten-year olds, the school science co-ordinator attended. Randomisation took place at the school level to avoid corruption between the intervention and control cohorts. The schools were matched into pairs based on pre-test results, EAL, FSM and size of school (Hanley et al 2015 p.8). Using random allocation, one of each pair was placed in the group engaging in using TDTS and the other continued with their usual practice (these schools were offered TDTS the following year, creating a delayed treatment control group).

Insert Table 2 
During the first year, two teachers from 21 participating schools received professional development training (as the intervention cohort). This consisted of the active involvement of the participants in all the TDTS strategies (including OOO, PMI, PP4T and BQ as described in Table 1), and in practical activities, together with professional dialogues about teaching and how to implement them in their own settings. A second group of 21 schools received this training in the academic year 2014-2015, forming the control group. In the absence of a nationally recognised science assessment, a test was developed using age appropriate, curriculum-relevant questions (Hanley et al 2015, p. 4, 11,36) that involved all the nine and ten-year olds in all 42 schools, at the end of the academic year.

The various complementary forms of qualitative data collected during the efficacy trial (EEF 2016) in-between the pre- and post-tests are presented and discussed below.

\section{Teachers' reflective questionnaires}

Each teacher involved in the TDTS project was invited to consider how their practice and their pupils' engagement in learning science had developed as a result of this intervention. The return of $57 \%$ of the evaluative questionnaires, administered via email after the fifth and final CPD day, provided responses from more than half of the teachers. The response rate from the teachers was lower than if they had been asked to complete the questionnaires on the day, whilst they were in-situ. As Cohen et al indicate (2018 p.501) more than 50\% respondees returning their questionnaires is satisfactory when they have to expend effort to return their replies. The responses to the questions were collated and inductively analysed for re-occurring themes. This approach was described by Peräkylä (2005) as a search for distinct descriptions where themes are inductively generated from the written accounts themselves. Strauss and Corben (1998) cited in Patton (2015) described this as a grounded approach. Brewer (2000) explains grounded theory as occurring when 'The properties of the codes are identified, leading to further refinement and revision of the codes to account for variations in the properties that have been identified. This inductive analysis saw underlying patterns of themes emerge from the original data. Each response was then categorised and tallied and then converted into individual frequency histograms which provided an overview of the teacher's perspectives (see Figure 4 and 5). Similarly, the teacher responses were also examined to explore why they thought girls and less able pupils might respond differently to the TDTS activities. The contrasts that teachers reported are summarised in Figure 6 and 7 substantiating their positive views of the TDTS approach that they noticed the boys responded enthusiastically to more practical experiences and the girls and those deemed less able appeared more engaged in discursive activities.

\section{Focus Groups}

The focus group data was collected from pupils nine months after their teachers had become involved in the TDTS project. Seven groups consisting of six nine and ten-year old pupils (three boys and three girls) from seven different primary schools, (identified through A-F pseudonyms, see Table 2 for further details) were invited to describe what they thought about the TDTS science lessons they had recently experienced. The questions probed their views of what they did, what they learned and what they thought about the science activities. These discussions were audio-recorded and transcribed. The transcriptions were analysed by adopting the 'themes' that emerged in the teacher's questionnaire responses, to enable crossreferencing and presentation of the most frequent comments that referred to doing, thinking and talking (see figure 8). This analytical approach is akin to Earle (2014) who analysed 91 science leaders' written reflections of primary school science assessment (both summative and formative). She found that although the teachers' written descriptions did not provide the rich data necessary to comprehensively evidence all aspects of impact there were some 
informative insights (ibid). Analysing the focus group comments for the same re-current patterns that the teacher recognised provides a clear comparison of the juxtaposed perspectives.

\section{Observational data}

Observational data from non-participating researchers was collated in two forms, i. field notes from professional development days involving the two cohorts (experimental and control) of teachers, and ii. audio-recordings of five classroom episodes that involved the Table 1 strategies. Field notes are drawn on to elaborate on the nature of the TDTS activities. The transcribed audio recordings of classroom episodes also provide illustrative descriptions of the nature of teacher and pupil interactions which demonstrate different aspects of Figure 2 and 3 in practice.

\section{Findings}

The collation and analysis of the datasets described earlier provided evidential information collected through the implementation of mixed research methods (Bennett et al 2019). The quantitative and qualitative data collated demonstrated the extent and nature of impact of the TDTS approach. The examination of the qualitative data, alongside the quantitative evidence of improved attainment, renders makes explicit the pedagogic processes that teachers utilised to challenge, invite, promote and encourage pupils' thinking. The findings are considered further, here, by reflecting on the two research questions:

1. What kinds of research methods can be applied to gather more qualitative evidence that complements the quantitative data demonstrating statistically that a particular intervention 'works'?

The EEF statistically assessed the impact of the TDTS training programme through an RCT involving 42 schools in a south east county. The results of the efficacy trial provided statistically proven evidence that the TDTS programme was successful in improving the science attainment of 525 pupils by an average of three months (Hanley et al 2015). The data gathered by the administration of pre and post-tests in both the experimental and control schools provided numerical data in the form of 'scores', that were statistically analysed. The pre-test data (a numerical value that represented each individual pupil's mark from a test of twenty science questions) provided the baseline scores. These scores for the pupils' post-test assessments from the intervention and control schools, were compared with the baseline data and analysed for the probability that the increase in attainment in the intervention schools could have happened by chance. Comparison of median scores and standard errors (Hanley et al 2015 p. 18) were calculated and shown to illustrate an effect size (Hedges 2007) of around 3 months' progress. The RCT comparison provided a method of measurement, Connelly et al (2017: 277) reasoned, that played a central role in seeking to determine whether an intervention had a discernible... effect on pupils' learning and development'. Whilst attainment levels in the intervention group exceeded the control group by approximately three months on average, it is not possible from this quantitative data and statistical handling of the test scores to be able to communicate clearly 'how' and 'why' the TDTS intervention worked to improve nine and ten year olds academic performance in science. Therefore, different kinds of research instruments beyond the 'tests', that paradigmatically assumed quantitative measures of scientific knowledge and understanding would evidence the extent to which the intervention was successful in improving attainment, were needed to examine and demonstrate 'how' the intervention worked in the 21 experimental classrooms. To review how the intervention 'worked' information was sought from participants to elicit their 
perspectives about how the TDTS was implemented and experienced in their schools. Paradigmatically, this more interpretative research dimension was designed to complement the quantitative evidence collated through the RCT, thus constituting a study resonating with a sequential mixed design (Teddlie and Sammons 2010). To assimilate ways that participants and onlookers viewed and interpreted the nature of TDTS required the employment of multiple research tools to collect insights from various perspectives. Collating teacher, learner and observers' perspectives of a phenomenon, in this case the enactment of TDTS in primary classrooms, various forms of data, elicited through observations, interviews, focus groups and questionnaires were sought.

Table 1, summarising how the five key types of activities comprising the TDTS approach make science 'more practical, creative and challenging' (EEF 2016) is clearly demonstrated through dialogic excerpts from discussions, descriptions of enactments and reflections about the intervention from both pupils and teachers. The qualitative data elicited through the implementation of various research tools (as outlined in Table 3) provided examples of the ways the cognitive and constructivist processes outlined in Table 1 were rehearsed and demonstrated by pupils in classrooms. These forms of reflective, dialogic and observational data would not be elicited as evidential impact if only the quantitative data had been collected. As Hanley et al (2016) suggest, the usefulness of RCTs, assessing 'what works' (p.288) is greatly enhanced when used in conjunction with evidence gathered from classroom practice as well as reflections from both teachers and pupils, providing insights that can substantiate 'why' and 'how' an intervention has been successful.

The qualitative data collected through various different research instruments (as summarised in Table 3) suggests how researchers' observational field notes of both the teachers engaging in the professional development program and then applying the TDTS approach in their classrooms offers clear exemplifications and descriptions of enactments of the practice associated with the intervention. This somewhat ethnographic approach enables a nonparticipant observer (Cohen, Manion and Morrison 2018) to 'see' how the TDTS approach has been interpreted by practicing teachers and enacted back in their own classrooms. This kind of qualitative data, therefore, verified the nature of the intervention, illustrating 'how' it worked in practice. The questionnaires that the teachers responded to also elicited their perspectives of changes in their practice and responses of the pupils to their implementation of the TDTS approach. This alongside the focus group interviews with the pupils triangulated and substantiated the characteristics of the social phenomena (Lofland 1971) of learning science through the TDTS strategies. Developing and applying a mix of research tools in this way provided juxtaposed ethnographic insights from teachers and learners supplemented by non-participant observations. Each perspective illuminating different facets of the interpreted, enacted and experienced TDTS approach. Therefore, the implementation of the complementary mixed methods evidenced in a comprehensive way the nature of TDTS pedagogy that successfully presented challenges to learners to nurture their affective capability, augment their scientific creativity and promote their thoughtful ingenuity to solve problems.

Insert Table 3

1. How does the intervention, TDTS, impact on teachers' practice to engage participating pupils in thinking and talking about science? 
Observations from the professional development activities and implementation of the TDTS approach in schools informed the evidence that illustrate why the approach worked. The strategies (as outlined in Table 1, with an indication of the potential cognitive processes to be promoted) enacted and witnessed in the observed classrooms are illustrated through descriptive vignettes. By posing questions such as, 'what do you think will happen when....?' extends an invitation to the pupils to construct their own personal view of a possible happening or subsequent event. If observations witnessed by pupils do not 'fit' their anticipations or currently held perceptions) then through discussion, re-consideration and comparison of their interpretations with others, their understandings will be affirmed or honed. This relates to the process of constructivism (as indicated in Figure 1) and enacted by TDTS teachers (as summarised in Figure 2). McGregor and Gunter (2006) illustrated how this technique, which does not constrain possibility thinking (Craft et al 2007), can elicit quite original and unique suggestions from pupils. Practitioners implementing the TDTS activities can promote either individual constructivism or encourage more social interaction (as indicated in Figure 3) to develop social constructivism. An example of PP4T, witnessed, includes a teacher asking pupils to consider what would happen when they place a lit candle under two balloons (the first balloon being normally inflated and the other, also inflated, but containing water in its base). In response to this particular challenge Frodsham (2017) observed pupils made suggestions such as: 'the candle will just go out [when placed under the balloon full of water]', 'it [the balloons] will definitely explode' or 'it [the water filled balloon] could shrivel up a bit but then not pop'. This illustrates the variation in the pupils' possibility thinking. Another PP4T challenge for pupils in TDTS witnessed by the researchers, is the cake tin positioned on its side at the centre of an inclined ramp and the onlookers are asked, 'What will happen?'. Unbeknown to the observers there is an internal mass attached inside, at an appropriate position, so that the force of gravity can turn the tin, when it is released and move it up the ramp. Thus, presenting learners with something they do not expect, characterising a Piagetian view of dissonance. Discussing how and why a tin can possibly move up an incline can engage them in using and applying scientific language to suggest ideas about the materials inside the tin, its position on the ramp and ways that different kinds of forces might cause alternate trajectories for the tin on the incline. Another conundrum presented to the pupils might be a coke can, not placed flat on the table, but balanced on a round bottom edge. The teacher asking, 'How is that possible?' prompts a range of replies that might suggest a particular liquid, magnet, sand or some other substance is inside it to enable it to balance in an unusual position. The very visual PP4T can therefore encourage the generation of scientific reasoning, prediction and hypothesizing. Engaging pupils to constructively consider and explain something they have not seen or experienced before is akin to the dissonance that Piaget refers to that results in accommodation (and then assimilation) promoting individual constructivism (as suggested in Figure 1).

A second strategy, OOO, encouraged the children to think through sorting and classifying objects and deciding whether or not they have something in common, or are distinctly different. For example, 'Which is the odd one out between a man, chimpanzee and teddy bear?' promotes thinking about features and characteristics of objects and encourages comparative analysis and synthesis (McGregor, 2007 : 241). Pupils are observed to proffer such ideas and reasoning as 'I think that the teddy bear is the odd one out because it doesn't consume any food or drink and it doesn't have any bones' (Frodsham, 2017). This approach is so flexible it can be adopted for use in any topic of science. Presenting the challenge, for example, deciding which is the odd one out, between water, chocolate and paper might promote thinking about the characteristics of solids and liquids, or diet and what might be 
ingested by humans or the extent to which these substances might be changed at lower or higher temperatures.

Another observed example includes that of a teacher who provided three pictures for the pupils to consider. In this case a lion, a London bus and a tree with all its green leaves. Given a couple of minutes to decide in pairs which was the odd one out the pupils were then told to explain their ideas using a 'because statement'. After a few minutes of intense discussion, the teacher picked up her pot full of lollipop sticks (with the pupil's names on) and asked three randomly chosen children their views. The first child said: 'The lion because he's the only one that is brown'. The second stated that: 'The bus was the odd one out because it's the only one that has wheels'. The third child stated confidently: 'The lion because it's the only one who lives in the desert'. The teacher added she thought the odd one out was the bus: '... because it was the only one that transported people from place to place'. Teachers' reflections after trialling this strategy felt that pupil discussions, in small groups, was very effective in eliciting a range of [justified or reasoned] ideas. They also recognised sometimes there needed to be some mediation to encourage thinking. This is exemplified by one teacher, from primary school A who presented the children with pictures of a log, chair and cat. Initially the pupils were flummoxed but after suggesting that the learners think about whether any were once living, many different ways of justifying which of the three things didn't 'fit' in the group were volunteered. Teachers were surprised, not only by how well this kind of stimulus worked to encourage talking about science, but also how extended the discussions became. This alongside the 'bouncing ideas off each other illustrated quite clearly how socially constructivist processes are valued by the teachers and that they actively sought ways to encourage them more often by laminating pictures of a range of objects and regularly and 'randomly' selected three to promote OOO discussions. Adopting this pedagogic strategy of introducing conundrums to encourage thinking promoted cognitive constructivist processes because it elicited pupils' reasoning and scientific justifications for their suggestions in the open-ended task for which there was no right or wrong answer.

The third approach, adopting deBono's (2000) PMI, also supports the generation of original ideas and suggestions emerging from the pupils. By posing a challenge, for example such as, if we had an extended power outage for some reason, and we lived in 'a world without electricity, what would be positive, what would be negative? what would be interesting?'. The pupils were observed constructing a whole host of propositions about consequences. Examples of positives include: 'children wouldn't have computers so they'd be outside more and fitter'; '[there would be] no electricity bills' and we 'wouldn't be able to make guns and weapons without electric powered factories'. Examples of negative comments included: 'no streetlights so they'd be security issues and crime might go up' and 'food would go off because [there would be] no fridges so [there] might be more food poisoning'. Interesting points included: 'steam power would make a comeback or solar power would be more common' and 'it would be like going back in time' (Wilson and Mant 2005: 22).

Another classroom adaptation of this strategy involved the teacher inviting the pupils to consider what would be positive, minus or interesting if one of the seven life processes described through the Mrs Nerg acronym (Movement, Respiration, Senses, Nutrition, Excretion, Reproduction and Growth) did not exist. After individual reflections, there was a whole class plenary where the following discussion emerged:

Child: $\quad$... if we didn't grow and everyone was really small, would everything around us become really tiny for us to be able to [...teacher talks over child...]. 
Teacher: Oh, what you're saying is [...] if all, if time stood still now, but we, in terms of growth, would there be some very tiny little things?

Would we have to adapt society for everything being small?

Child: $\quad$ Yeah $[\ldots]$ would they make water bottles smaller?

Teacher: [Laughs] Because we haven't grown?

Child: Yeah.

Teacher: I don't know. That is interesting.

(Frodsham 2017 : 247)

The PMI activity was set up so that there was an expectation that there was no correct answer (McGregor, 2007:253) thus providing the opportunity for the class to feel at ease enough to speculate (Davies, 2011:15).

The fourth approach also generated scientific reasoning, but not to explain a phenomenon or happening that can be concretely examined, but to consider a BQ, as outlined on table 1 . This approach, along with the OOO has been adapted and adopted by Explorify (Welcome Trust, 2019). This on-line platform presents intriguing photographs or illustrations of objects, events or organisms and asks a challenging open question, such as, 'What is going on here?', that could be answered in a range of ways. Other examples of BQs are: 'Where does the mass of the large tree come from?'; 'How do we know the earth is a sphere?' and 'How do I know I'm alive?'. Wilson et al (2017) notes how responses to these questions, from pupils, can range significantly. Firstly, when talking about the mass of the tree, pupil's comments include: 'the leaves suck in sunlight and convert into energy, using the chemical, chlorophyll. This process is called photosynthesis' [pupil ${ }_{1}$, school B] and 'it has come from the branches' [pupil 2 , school B]. Responses to thinking about the earth as a sphere, includes comments such as: 'Chris Colemba [sic] sailed around the world and he did not fall of [sic] the edge' [pupil, School C] and '...because gravity comes from the centre of the earth, because a sphere is the smallest shape you can make from the centre, it would most likely be pulled up into a sphere' [pupil 2 , school C]. Frodsham (2017) noted a range of responses, from nine and ten-year old pupils, to the question about 'How do you know you are alive?'. She noted that responses to the open-ended question, included: 'having/feeling a pulse', 'growing', 'being noticed', 'making objects move' and 'senses (feeling, touching and tasting)'. This illustrates, again, like OOO and PMI how teachers use these strategies in a constructivist way, eliciting unfettered ideas and suggestions from their pupils. The kinds of scientifically plausible responses to open queries that is encouraged by the teachers extends pupils' thinking and opens up opportunities for contributions from the whole class, no matter what their gender, ability or social background.

\section{Further teacher and pupil reflections}

Besides the very specific responses to the various pedagogic approaches described above, the teachers and pupils (aged 9-10 years from schools A-F) also commented generally about the intervention. Figure 4 illustrates how involvement in the TDTS approach has developed teachers' practices in science lessons and consequently affected the learning experiences of the pupils in their classrooms (figure 5). The most prominent pedagogic changes that the teachers reportedly implemented in their science classrooms, involved making science more interesting by doing more practical work, encouraging the pupils to talk and question more. They also reportedly provided more opportunities for pupils to make choices and/or determine what they did, independently of the teacher. 
It is interesting that three teachers, since participating in TDTS training, wrote, in their postevaluative questionnaire, about their personal growing enthusiasm for science. For example, 'I have found science far more enjoyable' and 'I enjoy the hands-on and the discussions'.

One teacher even highlighted how the parents of her pupils had praised her approach, 'Lots of positive comments at parents evening also made me feel like I was making a difference'. The inference here being that her pupils had communicated, back at home, how her creative teaching of science was augmenting their interest in the subject. This is likely because the TDTS programme had, as one teacher reported, enabled her ' ...to gain new ideas or think about different approaches to teaching Science that... helped engage, motivate and enthuse all children'. The pupils were also, according to the teachers, responding well to the new ways of learning science. That is, '...children react to this [approach] in a positive and enthusiastic way'. One practitioner stated, 'Pupils have been fully engaged in what they have been doing and have been forced to really think about [the] impact the experiments have had on their learning [ideas and thinking] and asked a lot more questions as to why that is'. This quotation infers active engagement, child-led experimentation and on-going class discussions. Additionally, there is an implicitly implied evaluative (critical) and 'childorientated' aspect to this teacher's view of her changed practice. Highlighted, clearly are more activities than previously to learn science, that involve the pupils, 'thinking', 'doing' and 'talking'.

Figure 5 corroborates how the teachers' reflectively report their changed practice. However, the pupils' comments also illustrate how they experienced the TDTS approach and reported increased interest, more experimental and practical work (Figure 8) as well as working (and discussing) more in small groups. Particular utterances from pupils included, 'we get like different things. ... we got to... choose' (pupil, school D). Another said, 'It's really fun because you get to make your... own decisions instead of the teacher ... making everything for you' (pupil, school F). This child's comment resonating with Piagetian constructivism and the intended aim of TDTS to develop pupils' thinking.

Being more engaged during a science lesson was frequently mentioned by the teachers (see Figure 4). The reported passion for science is also supported through the pupils' comments. A child, from school A, stated, 'I think...that doing science lessons in school is really fun and enjoyable because you get to do lots of activities'. Further to this another child, from the same school, noted how having fun does not mean that they would not be learning '...it's fun and.... it's nice to do lots of activities but still know that you're learning stuff'. This pupil was highlighting the art of enjoying scientific endeavour and juxtaposing it alongside their developing scientific understanding. In school $\mathrm{E}$ a child associates these fun activities with doing investigations, '....in more exciting science lessons we do experiments where we test out things'. Hands-on practicals are mentioned on various occasions by pupils from each of the seven schools. There are references to activities such as 'rocket mice' (school F) and 'bird beak adaptation' (school D). The former involves propelling a toy mouse through the air by rapidly squashing a plastic bottle launcher and the latter uses different sized paperclips to pick up food linked to the way that Darwin's finches adapted to their environment. One of the pupils, involved in the rocket mouse activity, indicated the nature of her thinking, 'I was kind of like thinking how it would work and I was thinking how the air would make the rocket mice work'. That is, she was thinking about and thinking with what she was learning (McGregor, 2007). Another child from the same school reported ' ...it gets your brain whizzing'. A third child from this suburban school, re-iterated how the 'doing' was important to support the thinking, she suggested, 'I wouldn't learn that much if we didn't do any handson activities or we didn't get shown anything. If we just read it from a piece of paper... I 
wouldn't learn as much as I do'. Interestingly, a comment from a pupil (in school G) also reflects, '.... when people like get together and do the fun stuff... you don't realise that you're kind of learning'. The act of getting together indicates how pupils value working with others in small groups in a socially constructivist manner. These young learners appear to recognise how working with others can help them develop their ideas. A pupil from school B said, 'when we're working with a partner...if you're stuck on a question or something in science then they can help you with what you're trying to answer' and 'I like to work in groups quite a lot... mainly due to the fact that...I like having people with me and supporting my ideas... instead of like going off by yourself' (pupil, school C). The implications here suggest how verbal exchanges with peers, working toward a common aim can help to extend their thinking into the zpd.

Problem-solving practicals, can enable learners to collaboratively negotiate solutions. Pupils, from school D described some activities their teachers presented to them. A year five boy provided details of how the class were invited to '...test [boats made out of play-doh and] how they floated... Then [he]... kept putting marble tiles into them... trying to see how many...they could fit...', A second boy explained further, '... if it didn't float we had to sort of make another model. And then we... kept putting marble[s] into them and... I found that really, really fun because it was... counting how many [marbles could be placed into the boats] and [then] making our boats better. The social interactions encouraged and enabled pupils to independently investigate their ideas and solve queries they came up with.

The TDTS activities mediate doing science, thinking about science and talking about science, which in combination as promoted by the pedagogic strategies (as outlined in Table 1) support learners' cognitive development (Hanley et al, 2015 p.8). The whole approach encourages learners to engage in constructive thinking (as detailed in Figure 2 and 3 ) and learning either on a solo basis or collaboratively with others. The focus on challenging the pupils and encouraging them to construe their own understanding from something experiential, in a constructivist manner, is at the very heart of the TDTS ethos.

\section{Discussion}

In considering a range of evidence, beyond that of a quantitative nature from the RCT tests, to include teachers' reflective questionnaires; pupils' focus group comments; field notes and audio recordings of enactments of TDTS in classrooms and on PD courses, the nature of the intervention is much clearer and detailed than just being 'more practical, creative and challenging' (EEF 2016). From the mixed method evidence presented here the nature of TDTS classroom practice (Sammons and Davis $2017: 490$ ) that is transformative (Creswell $2015: 17)$ is detailed from three perspectives, that of the teacher, the pupil and the researcher. The qualitative empirical evidence considered alongside the statistically significant quantitative evidence enables practitioners and researchers to better appreciate 'how' the intervention would work in their school, not just the extent to which it could improve attainment.

By examining the teacher's responses to the questionnaire, it is possible to discern that they believed the TDTS demonstrated how to open up classroom discussions and provide them with opportunities to further support pupils engagement in thoughtful conversations (Littleton and Mercer, 2013) and value those kinds of socially interactive learning opportunities. Additionally, pupils recognised that practical activities can produce various findings which could subsequently be debated openly. A learner stated, '...we try and do an experiment. ...then we would come back together and we see what variations and answers we had' (pupil 
in school D). This is evidence contrary to Hardman's (2008) generalised belief that teachers typically look for, and conduct lessons that convey a pre-specified answer. In fact, one teacher wrote 'the [TDTS] course [has] helped them [the pupils] to see that there are many things that we don't 'know'. This is evidence that a teacher, after TDTS training, recognised how science is not solely focussed on transmitting factual material and teaching testable content. It can be about thinking creatively rather than relying on the child to simply recall seemingly correct information when prompted (Alexander, 2008).

Child-led exploration was also frequently mentioned by the teachers as an outcome of the TDTS training. A teacher declared, 'I have tried to make them [the science lessons] more interactive with the children deciding on the question to be answered and allowing them time to investigate'. This approach can provide opportunities for the pupils to become the active agents of their own learning (McGregor, 2007) clearly resonating with a constructivist approach to developing thinking.

The comments from teachers and pupils were not just about asking questions and references to child-led explorations, verbal exchanges and the opportunity for pupils to voice their interpretations were also valued. To support this sentiment a teacher stated that the strategies had reportedly provided 'more opportunities to develop speech and ideas and consequently [children had become independently better] ... at [developing] ideas and explanations with evidence and reason[ing]'. What was also clearly evident was the pupils' recognition that they could help facilitate each-others' thinking. They became able, in a socially constructivist sense, to mediate another's zpd. They [the pupils] felt they were empowered to be in the role as the knowledgeable other. As one pupil stated, '...now I can be an expert and go and like help people'. Teachers also acknowledged this change in the pupils' behaviour when they reflected, '...it has allowed them [the pupil] to become the teacher'.

In the data outlined here evidence from teachers, pupils and observers (non-participant researchers) have recognised how the TDTS approach promotes science learning that is more child-led, discursive, less transmissive and factually oriented and more exploratory in nature. Talking about science featured prominently in the written reflections and it was clearly evident in the professional development sessions and lesson observations. These observations, for example, illustrate how the activities, offer opportunities to think differently and not necessarily conform to expectations,

'Not all students have the same idea as their teachers about what they are meant to be doing in the classroom. For a simple example, we might ask students which is the odd one out in the following list of objects: knife, fork, hammer, bottle of ketchup. Some students will say that the bottle of ketchup is the odd one out, because the others are all metal tools. Other students will say that the hammer is the odd one out because the other objects can be found on the kitchen table at mealtime. Of course, in an absolute sense, neither of these two answers is better than the other, but as Nell Keddie (1971) pointed out years ago, schools place a greater value on the first way of thinking about the world than the second.'

(Wiliam 2011 p.52)

The teaching strategies (outlined in Table 1) facilitated inclusive constructivist learning (also summarised in Table 4) and the ways that scientific ideas were considered and made accessible for all pupils meant that girls (Figure 6) and the less able (Figure 7) could participate in, and perform at a variety of levels in the doing, thinking and talking tasks. Pupils recognised the value of discussion, that facilitated their use of scientific language and developed their literacy (Harlen 2014) through others mediating, promoting and extending their thinking (as indicated in figure 3). 


\section{Conclusion}

The EEF (2016) states that the TDTS training programme and its adoption in primary classrooms would, according to their website, '...make science lessons more creative, practical and challenging'. However, without the complementary research evidence that is elicited through a mixed methods approach, required to collect and analyse a range of forms of qualitative data it is not possible to substantiate 'how' and ' $w h y$ ' the TDTS approach can affect a 3-month improvement in nine-ten year olds' academic attainment. The pre and posttest data, collected through an RCT that provides statistically significant evidence of an intervention that is successful in improving attainment, does not inform 'how' it works and clearly indicate for other teachers, outside the intervention, what they should pay attention to if they wish to ensure a similar result with their own nine and ten-year old classes. As Harlen (2009) would argue a single test can-not accurately gauge the nature of development of a child's developing cognition (or knowing). Research tools including questionnaires, focus group discussions and observations of training and the implementation of teaching TDTS insitu suggests how practice could be characterised to 'work' and improve attainment. The key features of the TDTS pedagogy that make a significant difference includes an underpinning emphasis of a constructivist approach. Presenting conundrums or challenges in different forms, ranging from the cognitive, as illustrated by PP4T, OOO and PMI, to the practical problem solving that involves pupils' engaging in doing science characterises the nature of the learning tasks. The TDTS approach also values creative, ingenious and alternate ways of thinking, explaining and talking about scientific phenomena. In other words, teachers knowing how and when to use particular materials, sequence and pose questions, encourage discussion, mediate without giving away any answers (McGregor 2007: 161 - 164) will affect how pupils engage in thinking. Finally, both teachers and pupils recognising that they all, as participants in a classroom community, can engage in socially constructivist processes each mediating the others' thinking or zpd consolidates how TDTS promotes equitable opportunities for participation and contribution from all pupils across genders and economic classes. Therefore, as Bennett et al (2019) have argued, a mixed methods research approach is required to insightfully and informedly elicit and evidence how and why a successful intervention, such as TDTS can make a significant difference to pupils' thinking prowess and improved academic performance in school. Without a mixed methods research approach informing how the TDTS approach successfully 'makes science more practical, creative and challenging' teachers might not appreciate how to epistemically ensure their pupils experience the doing, thinking and talking in the most effectively constructivist way.

\section{References}

Adey, P. and Shayer, M. (1994) Really Raising Standards. London: Routledge

Alexander, R. (2008) Essays on Pedagogy. Abingdon: Routledge.

Bennett, J., Hanley, P., Abrahams, I., Elliot, L. and Turkenburg-van Diepen (2019) Mixed Methods, Mixed outcomes? Combining an RCT and case studies to research the impact of a training programme for primary school science teachers. International Journal of Science Education. pp. 490 - 509 https://doi.org/10.1080/09500693.2018.1563729

Bredo, E. (1999) Reconstructing educational Psychology. In Learner's, Learning \& Assessment, edited by P. Murphy, 23 - 45. London: Paul Chapman Publishing Ltd. 
Brewer, J. D. (2000) Ethnography. Buckingham: Open University Press.

Brown, A. L., \& Ferrara, R. A. (1985) Diagnosing zones of proximal development. Culture, communication and cognition: Vygotskian perspectives, edited by J. V. Wertsch, 273 - 305. London : Cambridge University Press.

Bruner, J.S. (1996) The Culture of Education. Cambridge, Mass.: Harvard University Press.

Cohen, L., Manion, L., and Morrison, K. (2011) Research Methods in Education (7th ed.). London : Routledge.

Connolly, P., Keenan, C., and Urbanska, K. (2018) The trials of evidence-based practice in education: a systematic review of randomised controlled trials in education research 1980-2016 Educational Research 60 (3) 276-291

Craft, A.; Cremin, T.; Burnard, P. and Chappell, K. (2007). Developing creative learning through possibility thinking with children aged 3-7. In Creative Learning 3-11 and How We Document It, edited by A. Craft, T. Cremin and P. Burnard, 65 - 74. London, UK : Trentham.

Craft, A., Cremin, T., Hay, P., and Clack, J. (2014) Creative primary schools: developing and maintaining pedagogy for creativity. Ethnography and Education 9 (1) 16-34

Cresswell, J.W. (2015) A Concise Introduction to Mixed Methods Research. London : Sage

de Bono, E. (1967) The Use of Lateral Thinking. Harmondsworth: Penguin.

de Bono, E. (1993) Teach your child how to think. Penguin: London.

Dillon, J. (1994) Using Discussion in Classrooms. Buckingham: Open University Press.

Earle, S. (2014) Formative and summative assessment of science in English primary schools: evidence from the Primary Science Quality Mark Research in Science \& Technological Education 32 (2) 216-228.

Education Endowment Foundation (EEF) (2018) Thinking, Doing, Talking Science. Regrant. https://educationendowmentfoundation.org.uk/projects-andevaluation/projects/thinking-doing-talking-science-effectiveness-trial/(Accessed 23.7.19)

Education Endowment Foundation (EEF) (2019a) The big picture. Retrieved from https://educationendowmentfoundation.org.uk/school-themes/(Accessed 23.7.19)

Education Endowment Foundation (EEF) (2019b) Philosophy for Children. Retrieved from https://educationendowmentfoundation.org.uk/pdf/generate/?u=https://educationendo wmentfoundation.org.uk/pdf/project $/ ? \mathrm{id}=162 \& \mathrm{t}=\mathrm{EEF} \% 20$ Projects $\& \mathrm{e}=162 \& \mathrm{~s}=$ (Accessed 23.7.19)

Education Endowment Foundation (EEF) (2019c) Dialogic Teaching. Available at 
https://educationendowmentfoundation.org.uk/pdf/generate/? $\mathrm{u}=\mathrm{https}: / /$ ducationendo wmentfoundation.org.uk/pdf/project $/$ id $=235 \& \mathrm{t}=\mathrm{EEF} \% 20$ Projects $\& \mathrm{e}=235 \& \mathrm{~s}=$ (Accessed 23.7.19)

Fosnot, C. T. (2005) Constructivism: Theory, Perspectives and Practice. New York: Teachers College Press:

Fosnot, C.T (1989) Enquiring teachers, enquiring learners: A constructivist approach for teaching. New York: Teachers College Press.

Fisher, A. (2001) Critical thinking: an introduction (2nd ed.). Cambridge: Cambridge University Press.

Frodsham, S. (2017) 'Developing creativity within primary science teaching. What does it look like and how can classroom interactions augment the process?'. $\mathrm{PhD}$ thesis. Oxford: Oxford Brookes University.

Griggs, G. and McGregor, D. (2012) Scaffolding and mediating for creativity: Suggestions from reflecting on practice in order to develop the teaching and learning of gymnastics. Journal of Further and Higher Education 36 (2) 225 - 242.

Hanley, P., Slavin, R. and Elliot, L. (2015) Thinking, Doing, Talking Science. Evaluation Report and Executive Summary. York : Institute of Effective Education/Education Endowment Foundation (EEF) Retrieved from https://educationendowmentfoundation.org.uk/evaluation/projects/thinking-doingtalking-science/(Accessed 09.06.19).

Hardman, F. (2008) Teachers' Use of Feedback in Whole-class and Group-based Talk. In N. Mercer and S. Hodgkinson (Eds.), Exploring Talk in School (pp. 131-150). London: Sage.

Harlen, W. (2009) Improving assessment of learning and for learning. Education 3-13 37 (3) 247-257.

Hedges, L.V. (2007) Effect sizes in cluster-randomized designs. Journal of Educational and Behavioural Statistics 32 (4) 341 - 370

Hetherington, L., Chappell, K., Ruck-Keene, H., Slade, C., Bogner, F., and Sotiorou, S. (2018)

European educators' perspectives on the relationship between Science and Creativity, and implications for pedagogy. Paper presented at IOSTE Symposium. $14^{\text {th }}$ August 2018.

Johnston, J. (2007) What is creativity in science education. In Creativity in Primary Education (2nd ed) edited by A. Wilson, 77 - 93. Exeter: Learning Matters Ltd.

Kitmitto, S., González, R., Mezzanote, J., \& Chen, Y. (2018) Thinking, Doing, Talking Science: Evaluation report and executive summary. London: EEF.

Lofland, J. (1971) Analysing Social Settings. Belmont, CA : Wadsworth. 
Marzano, R. J. (2001) A New Taxonomy of Educational Objectives. In Developing minds: A Bookfor Teaching Thinking edited by A. L. Costa, 181-188. Alexandria: ASCD.

McGregor, D. (2007) Developing Thinking, Developing Learning: A Guide to Thinking Skills in Education. Maidenhead: Open University Press.

McGregor, D. (2013) Using children's ideas in teaching: reviewing messages from research. Education in Science November Issue p.24 - 25

McGregor, D., \& Gunter, B. (2006) Invigorating pedagogic change. Suggestions from findings of the development of secondary science teachers' practice and cognisance of the learning process. European Journal of Teacher Education 29(1) 23-48.

McGregor, D. \& Frodsham, S. (2019) 'Epistemic insights: Contemplating tensions between policy influences and creativity in school science'. British Educational Research Journal 45 (4) 770 - 790

Mercer, N. (2008) Three kinds of talk. Retrieved from https://thinkingtogether.educ.cam.ac.uk/resources/5 examples of talk in group s.pdf (Accessed 19th Apr 2016).

Mercer, N., \& Hodgkinson, S. (2008) Exploring Talk in School. London: SAGE.

Millar, R. (2011) Vygotsky in Perspective. Cambridge: Cambridge University Press.

Patton, M. Q. (2015) Qualitative Research \& Evaluation Methods (2nd ed) London: SAGE.

Peräkylä, A. (2005) Analyzing Talk and Text. In The SAGE Handboook of Qualitative Research (3rd edn), edited by N. K. Denzin and Y. S. Lincoln, 869 - 886. London: SAGE.

Piaget, J. (1950) The psychology of intelligence. London: Routledge

Piaget, J. (1959) The language and thought of the child (3rd edn) London: Routledge

Piaget, J. (1970) The Principles of Genetic Epistemology London: Routledge.

Polanyi, M. (2005) Personal Knowledge: Towards a Post-critical Philosophy London: Routledge.

Robinson, K. (2001) Out of Our Minds : Learning to be Creative. Chichester: Capstone Publishing Ltd.

Robinson, K. (2009) The Element: How Finding Your Passion Changes Everything. London: The Penguin Group.

Sammons, P. and Davies, S. (2017) Mixed Methods Approaches and their Application in Educational Research. In The BERA/SAGE Handbook of Educational Research, edited by D. Wyse, N. Selwyn, E. Smith and L. Suter, 477 - 504. London : SAGE 
Science Oxford (2019) Thinking Doing Talking Science. Available at https://tdts.org.uk Accessed 06.08.19

Siraj-Blatchford, R., and Manni, L. (2008) 'Would you like to tidy up now?' An analysis of adult questioning in the English Foundation Stage Early Years 28 (1): 5-22.

Stylianidou, F., Glauert, E., Compton, A., Riley, A., Cremin, T., Clack, J., and Craft, A. (2014) Creative little Scientists Project - Enabling creativity Education in Science 257 (Sept) 30-31

Teddlie, C. and Sammons, P. (2010) Applications of mixed methods to the field of educational effectiveness research. In Methodological Advances in Educational Effectiveness Research, edited by B. Creemers, L. Kyriakides and P. Sammons, 115 152. London : Routledge Taylor \& Francis

Tsou, J. Y. (2006) Genetic Epistemology and Piaget's Philosophy of Science Piaget vs. Kuhn on Scientific Progress. Theory \& Psychology 16 (2) 203 - 224

Vygotsky, L. S. (1978) Mind in society: the development of higher psychological processes. London: Harvard University Press.

Wiliam, D. (2011) Embedded Formative Assessment Bloomington, IN : Solution Tree Press

Wilson, H. and Mant, J. (2005) Creativity and Excitement in Science. Oxford Brookes University: Astra Zeneca and Oxford Brookes University

Wilson, H., McGregor, D., Bird, J., \& Frodsham, S. (2017) Creativity in Primary Science: Illustrations from the classroom. Bristol: PSTT.

Wyse, D., Brown, C. Oliver, S. and Poblete, X. (2018) The BERA Close to Practice Research Project. Research Intelligence. p. 15 - 16 Retrieved from: https://www.bera.ac.uk/wp-content/uploads/2018/11/J05387-BERA-RI-137-04WEB.pdf Accessed 23.7.19

Wood, D. (1992) Teaching Talk. In K. Norman (Ed.) Thinking Voices London: Hodder \& Stoughton

Wood, D., Bruner, J. S. and Ross, G. (1976) The role of tutoring in problem solving. Journal of child psychology 17 p.89 - 100 
ORIENTATION

(the TDTS activities are presented)

\author{
$\downarrow$ \\ ELICITATION \\ OF IDEAS
}

(what children think is explored through talking about what has been presented/observed/experienced)

\title{
$\uparrow$ \\ DEVELOPMENT OF THINKING
}

(is encouraged by the teacher through mediating whole class or small group discussion, considering possibilities, developing predictions, explanations, resolutions to problems)

Figure 1: Elements of constructivist pedagogy adopted in TDTS. 


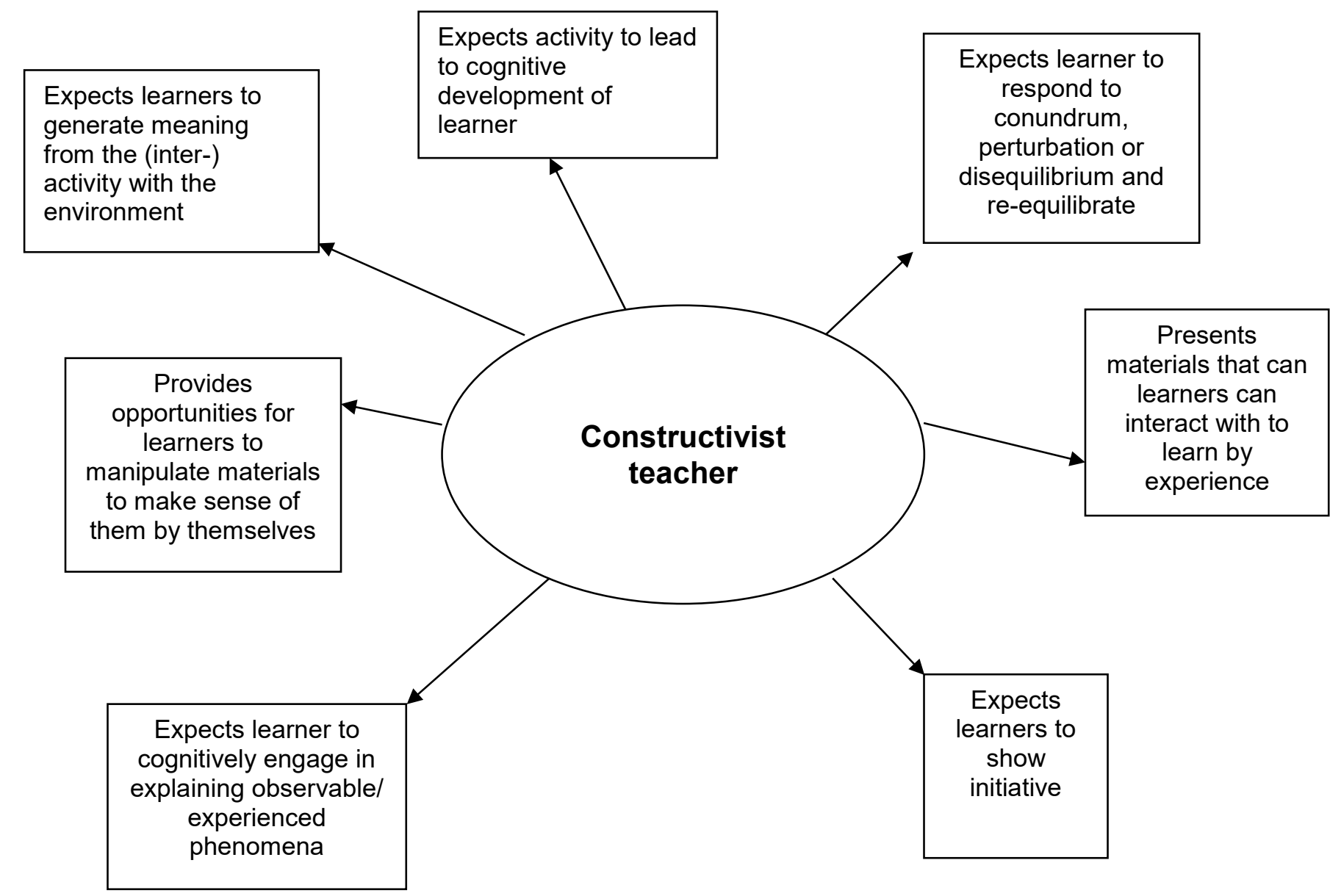

Figure 2: Prominent teacher behaviours and expectations implied by the constructivist view of thinking and learning (adopted from McGregor 2007). 


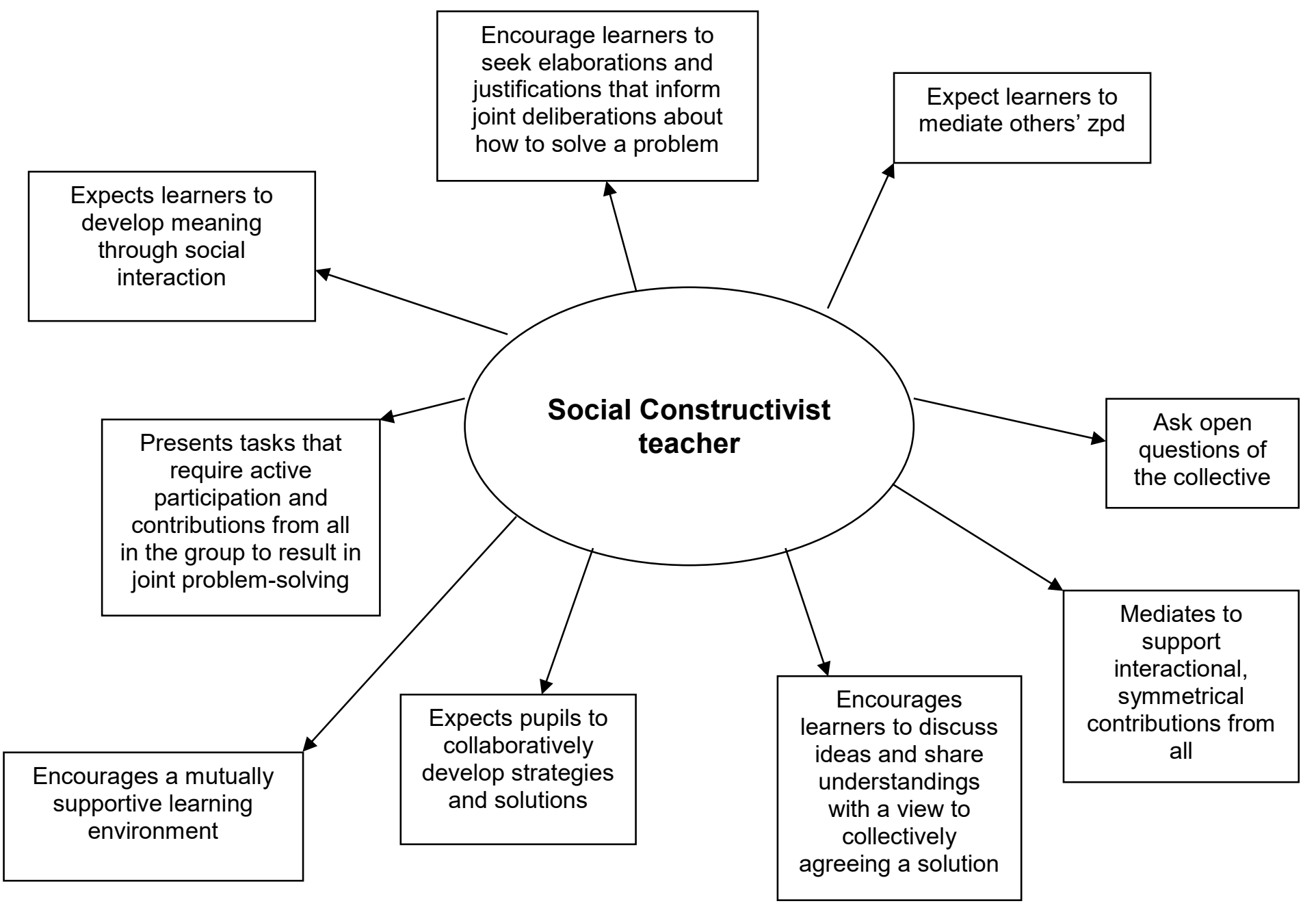

Figure 3: Prominent teacher behaviours and expectations implied by the social constructivist view of thinking and learning (adopted from McGregor 2007). 


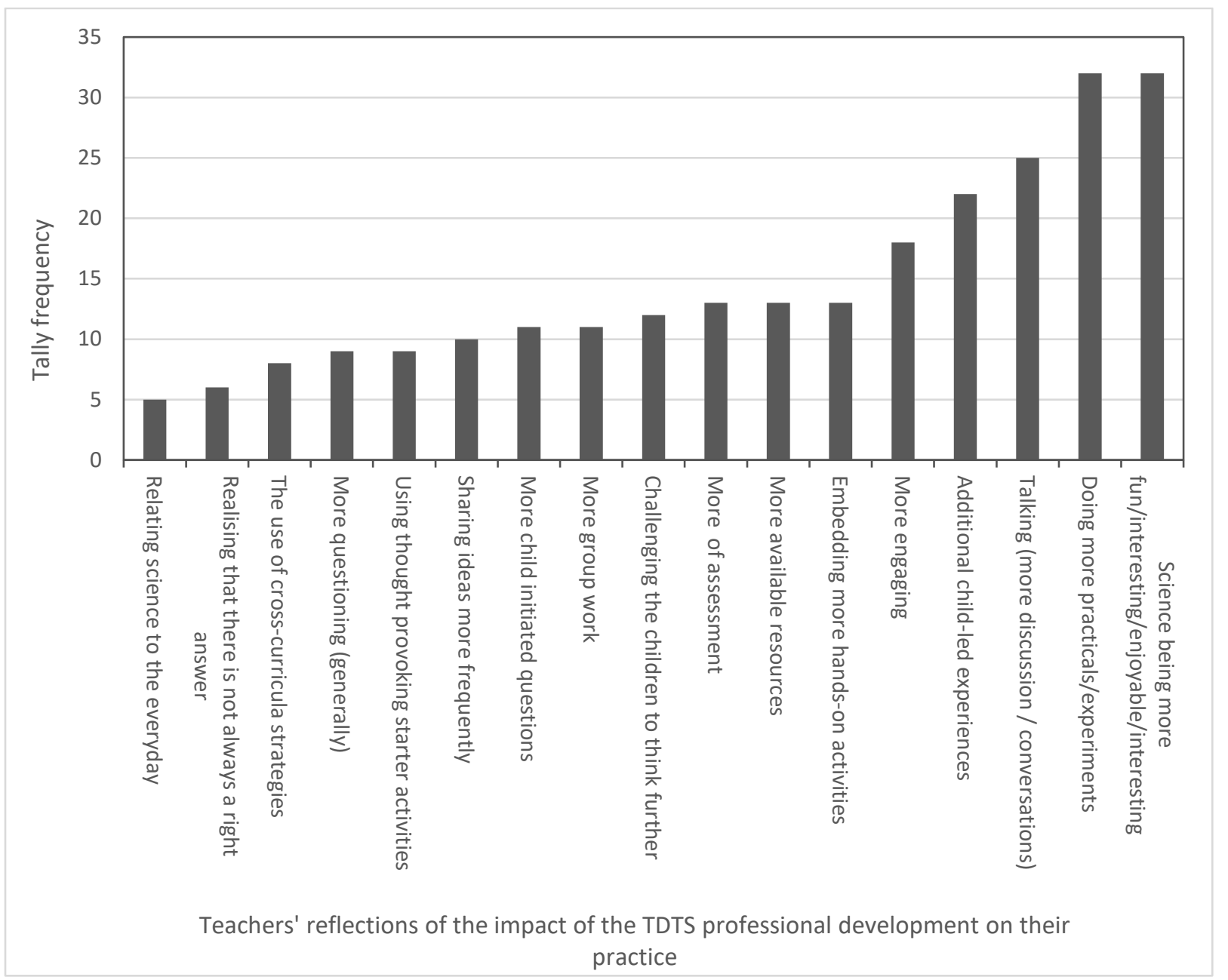

Figure 4 : Most prominent pedagogic changes reported by primary school science teachers in the 2013-2014 trials of the TDTS project $(n=47)$.

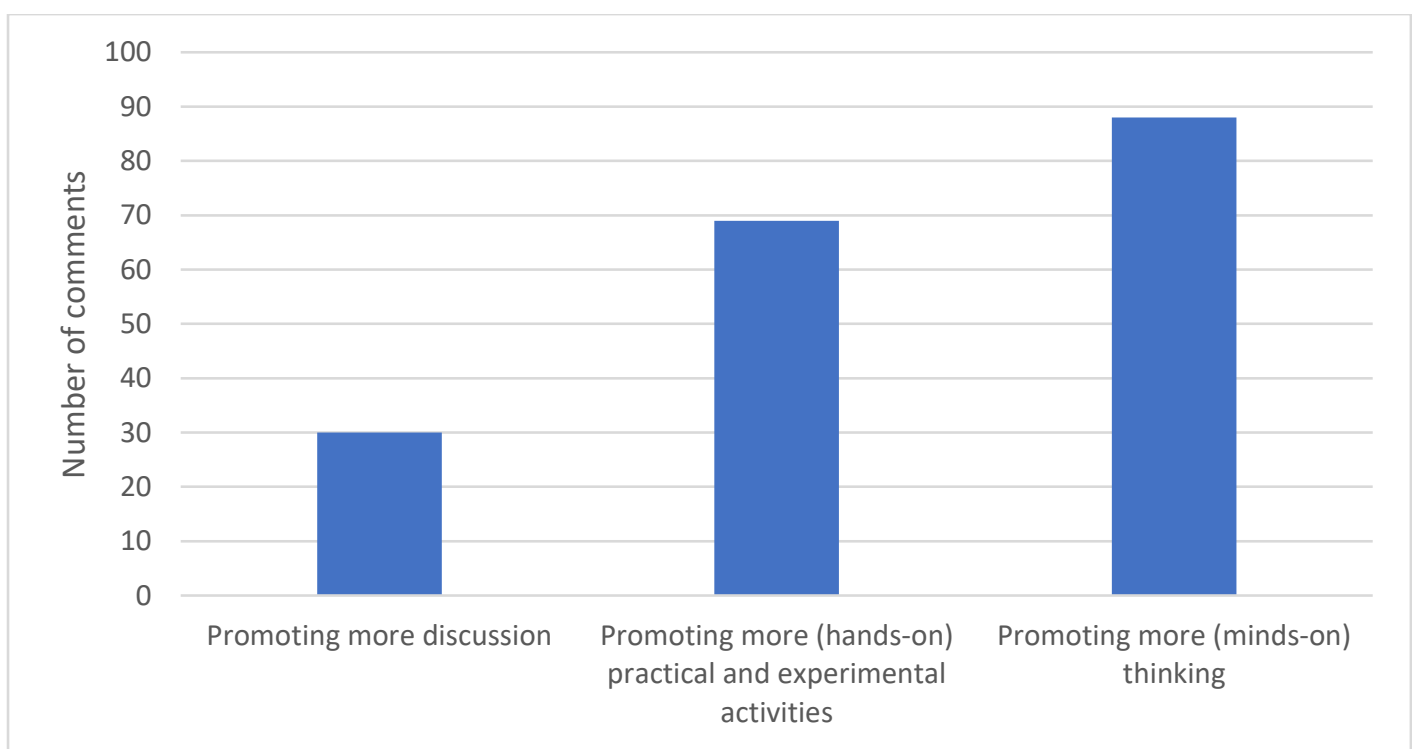

Figure 5. Summary of the pedagogic changes reported by the pupils after using 'Thinking', 'Doing' and 'Talking' activities. 


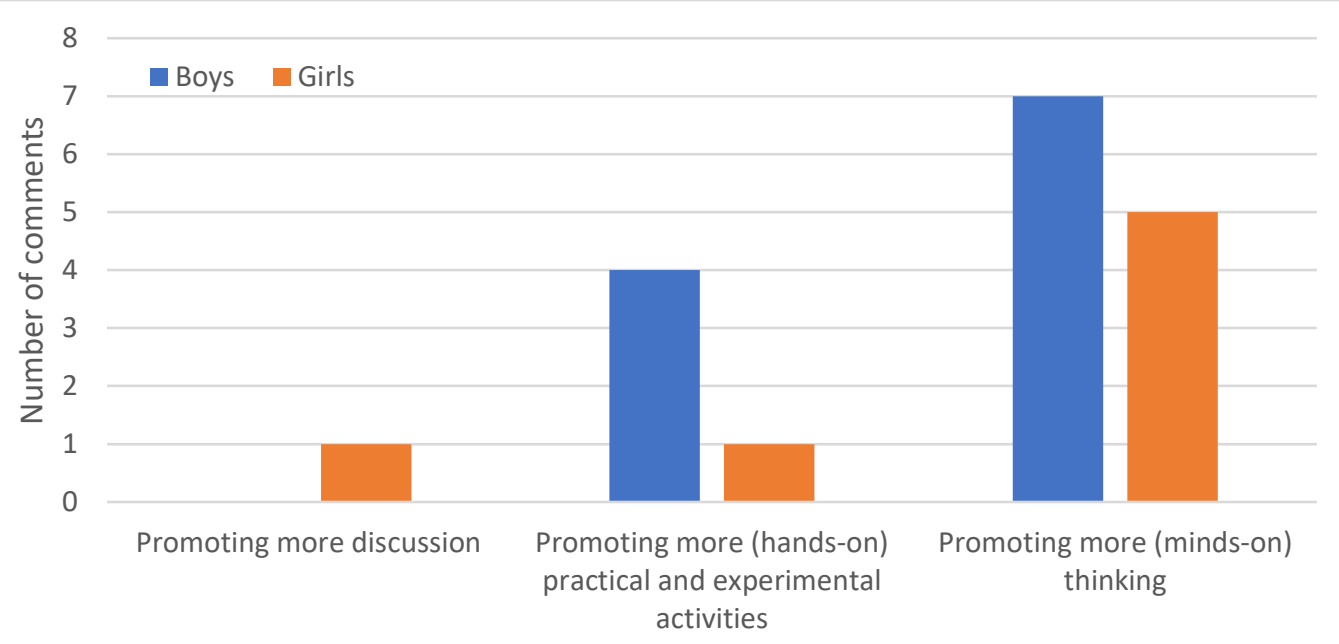

Figure 6 : To indicate teacher's mentions in questionnaires of their views of the different responses of boys and girls $(n=12)$.

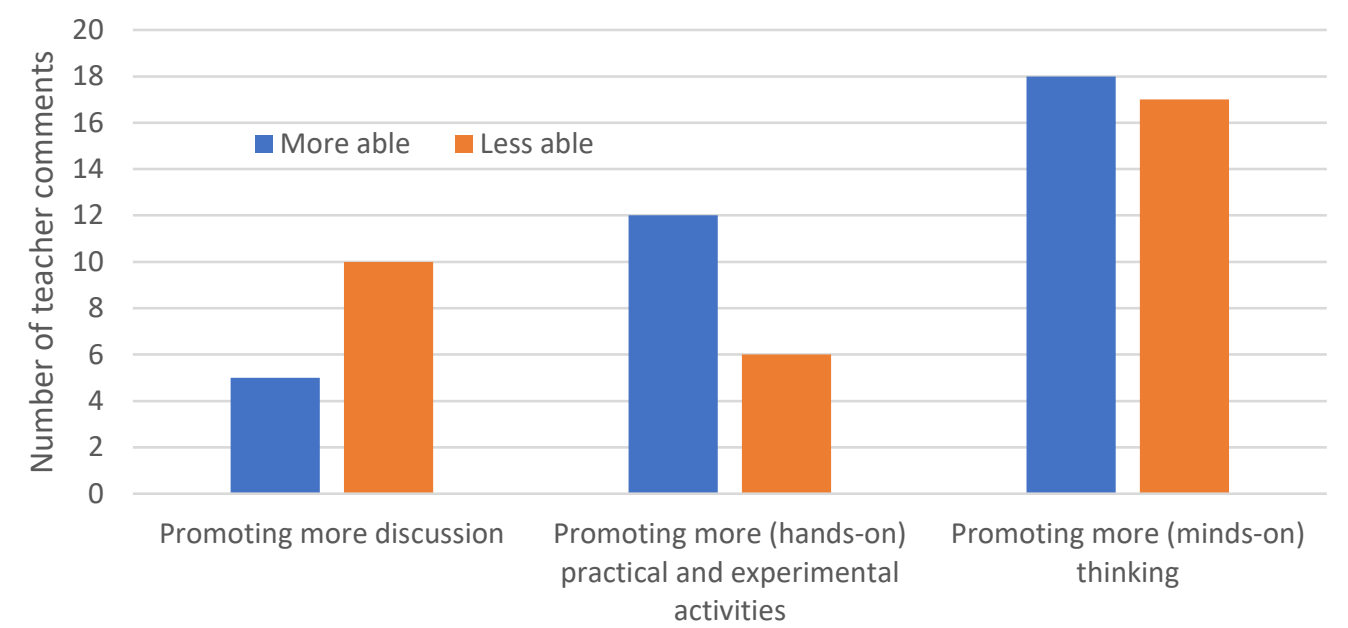

Figure 7 : To indicate teacher's mentions in questionnaires of their views of the different responses more and less able pupils $(n=47)$. 


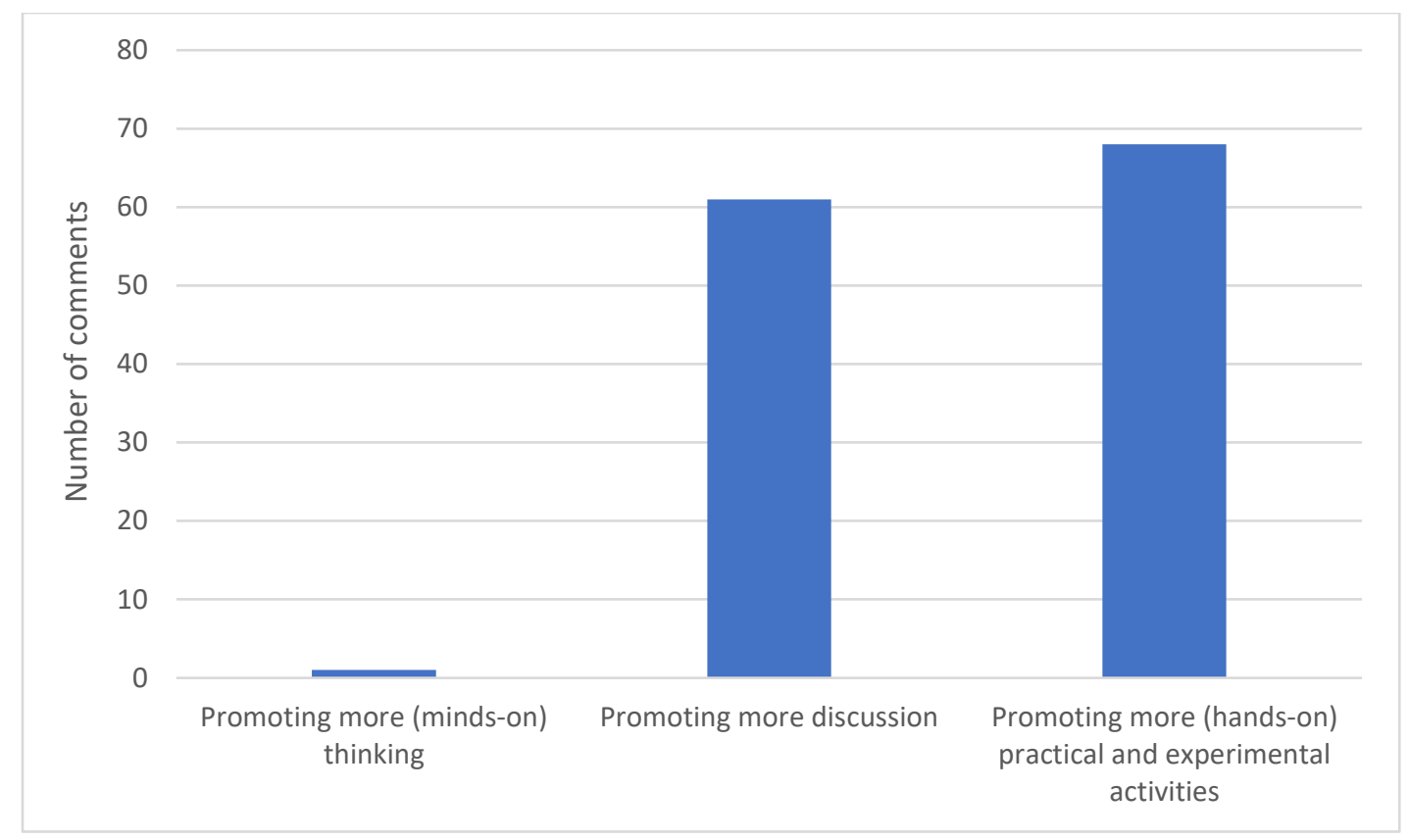

Figure 8 : Summary of the pedagogic changes to 'Thinking', 'Doing' and 'Talking' from the pupils (aged 9-10) perspective $(n=36)$. 


\begin{tabular}{|c|c|c|c|}
\hline \multicolumn{2}{|c|}{ TDTS Activity } & $\begin{array}{c}\text { Nature of potential cognitive functions } \\
\text { practiced in activity }\end{array}$ & $\begin{array}{l}\text { Illustrating how the TDTS approach can } \\
\text { promote constructivist learning } \\
\text { opportunities }\end{array}$ \\
\hline & $\begin{array}{l}\text { Practical } \\
\text { prompt } \\
\text { for } \\
\text { thinking } \\
\text { (PP4T) }\end{array}$ & $\begin{array}{l}\text { Possibility thinking } \\
\text { Reasoning about observations } \\
\text { Anticipating consequences } \\
\text { Predicting and hypothesizing }\end{array}$ & $\begin{array}{l}\text { Inviting suggestions about how a cake tin } \\
\text { balanced on its side can move up an } \\
\text { incline. }\end{array}$ \\
\hline & $\begin{array}{l}\text { Odd One } \\
\text { Out (OOO) }\end{array}$ & $\begin{array}{l}\text { Recognising relevant characteristics or } \\
\text { features of objects } \\
\text { Sorting and classifying objects through } \\
\text { consideration of characteristics or } \\
\text { features of objects } \\
\text { Comparing and contrasting information } \\
\text { Identifying and analysing connections } \\
\text { and/or relationships between objects } \\
\text { Reasoned judgements }\end{array}$ & $\begin{array}{l}\text { Presenting water, chocolate and paper } \\
\text { and asking which is the odd one out, with } \\
\text { reasons. }\end{array}$ \\
\hline c. & $\begin{array}{l}\text { Positive } \\
\text { Minus } \\
\text { Interesting } \\
\text { (PMI) }\end{array}$ & $\begin{array}{l}\text { Generating suggestions } \\
\text { Giving reasons for opinions } \\
\text { Inferring } \\
\text { Making deductions } \\
\text { Thinking about cause and effect } \\
\text { Linking and connecting things } \\
\text { Anticipating consequences }\end{array}$ & $\begin{array}{l}\text { What would be positive, negative and } \\
\text { interesting in a world without electricity? }\end{array}$ \\
\hline d. & $\begin{array}{l}\text { Big } \\
\text { Questions }\end{array}$ & $\begin{array}{l}\text { Reasoning about observations } \\
\text { Using precise and scientific language to } \\
\text { explain things }\end{array}$ & How do we know the earth is a sphere? \\
\hline & $\begin{array}{l}\text { Problem } \\
\text { Solving }\end{array}$ & $\begin{array}{l}\text { Asking questions } \\
\text { Generating ideas } \\
\text { Predicting and hypothesizing } \\
\text { Planning and sequencing actions } \\
\text { Judging success of actions } \\
\text { Evaluative thinking }\end{array}$ & $\begin{array}{l}\text { Which boat design can carry the most } \\
\text { mass? }\end{array}$ \\
\hline
\end{tabular}

Table 1: A summary of key teaching strategies adopted by TDTS and the nature of thinking they can promote. 


\begin{tabular}{|c|c|c|}
\hline School pseudonym & Age range of pupils & Number on roll \\
\hline A & $4-11$ & 106 \\
\hline B & $3-11$ & 391 \\
\hline C & $3-11$ & 426 \\
\hline D & $4-11$ & 205 \\
\hline E & $3-11$ & 217 \\
\hline F & $4-11$ & 416 \\
\hline G & $3-11$ & 449 \\
\hline
\end{tabular}

Table 2: The schools (A - E, from a county in south east England) involved in the focus group data collection.

\begin{tabular}{|l|l|}
\hline Research instrument implemented & Nature of data gathered \\
\hline Questionnaires responded to be teachers & $\begin{array}{l}\text { Reflective written accounts of teachers } \\
\text { personal experiences of the use of TDTS } \\
\text { activities. }\end{array}$ \\
\hline Pupils focus group discussions. & $\begin{array}{l}\text { Transcriptions of pupils' descriptions of } \\
\text { their verbalised recollections of the } \\
\text { experiences with TDTS. }\end{array}$ \\
\hline Audio-recorded discussions & $\begin{array}{l}\text { Transcripts of dialogue that emerges in } \\
\text { TDTS activities. }\end{array}$ \\
\hline Researchers observational field notes & $\begin{array}{l}\text { Non-participant observations of visual and } \\
\text { auditory enactments, by both pupils and } \\
\text { teachers, of TDTS in school classrooms. }\end{array}$ \\
\hline
\end{tabular}

Table 3 : The nature of qualitative data collected through questionnaires, focus groups, observations and field notes.

\begin{tabular}{|c|c|c|}
\hline & TDTS Activity & Element of constructivism clearly demonstrated \\
\hline f. & $\begin{array}{l}\text { Practical prompt for } \\
\text { thinking (PP4T) }\end{array}$ & $\begin{array}{c}\text { The learner responds to the conundrum, perturbation or } \\
\text { disequilibrium and re-equilibrates their ideas. } \\
\text { The learner cognitively engages in explaining observable/experienced } \\
\text { phenomena. }\end{array}$ \\
\hline g. & Odd One Out (OOO) & $\begin{array}{c}\text { Opportunities are provided for learners to [mentally] manipulate } \\
\text { materials to make sense of them by themselves. }\end{array}$ \\
\hline h. & $\begin{array}{l}\text { Positive Minus } \\
\text { Interesting (PMI) }\end{array}$ & Engaging in the activity promotes cognitive development of learner. \\
\hline & Big Questions & $\begin{array}{l}\text { The learner generates meaning from the (inter-) activity with the } \\
\text { environment. }\end{array}$ \\
\hline & Problem Solving & $\begin{array}{c}\text { The presentation of materials that the learner can interact with } \\
\text { provides learning by experience. } \\
\text { The learner should show initiative. }\end{array}$ \\
\hline
\end{tabular}

Table 4: A summary of the ways each TDTS teaching strategy characterises an aspect of constructivism. 